\title{
Mechanical model for 2D steel joints with beams of different depth without web stiffeners.
}

\author{
[M.López, A. Loureiro, E.Bayo]
}

\begin{abstract}
Joints play a very important role in steel structures from the points of view of safety and optimization. In recent years progress has been made in the characterization of the behaviour of steel joints. Part of the knowledge has been integrated in the design codes, and EC3 in particular. In this code the component method has been proposed for connection analysis. However, not all the possible cases are included. One of the configurations that need to be studied is the joint studied in this research: it is a welded internal joint with beams of different depth and without stiffeners. A parametric analysis, based on previously calibrated finite element models is carried out. From the results of this analysis, the expressions for the components that form the mechanical model of the joint are proposed.
\end{abstract}

Keywords - Semirigid joints, Steel structures, Mechanical model, Parametric analysis

\section{Introduction}

In the last years an important research has been done with the aim of advancing the knowledge on the behaviour of steel joints under the point of view of stiffness and resistance. In this sense, it is worth mentioning the works of Krawinkler et al. [1], Faella et al. [2], Curtis and Greiner [3], and Hashemi and Jazany [4]. Eurocode 3 [5] uses the component method for the analysis of the $2 \mathrm{D}$ joints. This method is difficult in its application, and is not applicable in several of the habitual joints. Recently, Bayo et al. [6] [7] \& [8], M. Lopez et al. [9] and A. Loureiro et al. [10] have studied joints with additional plates, the interaction between axes in 3D joints, the behaviour of trapezoidal column web in shear, and that of the double web panel with stiffeners. This research has lead to the development of mechanical models and cruciform elements that take into account the real dimensions of the joints and avoid the use of the $\beta$ parameter proposed in the EC3.

M. López and A. Loureiro

University of A Coruña

Spain

E. Bayo

University of Navarra

Spain
One of the joints that have not yet been analyzed in depth, is the joint proposed in the present work. It is a $2 \mathrm{D}$ beam to column welded connection, with beams of different depth in both sides of the column, and without stiffeners in the column web. In order to study the joint, calibrated finite elements models have been used. The methodology for determining the stiffness of the different components of the proposed mechanical model is similar to that previously used in other works done by the same authors. This leads to the proposal of a formulation for the different components that constitute the mechanical model of the joint.

\section{Parametric analysis}

The parametric analysis has been done using the Abaqus program. The numerical models have been calibrated with the results of previous studies of Loureiro et al [10]. Nonlinear analysis has been used, to take into account the nonlinearity of the material. The real mechanical properties of the material have been introduced in the analysis. The Von Misses yield criterion was selected to define the inelastic response. The finite elements models were performed using Abaqus with solid elements (C3D8R) featuring reduced integration and hourglass control.

In the parametric analysis a total of 16 different configurations have been studied. Table 1 shows those configurations.

TABLE I. CONFIGURATIONS OF THE PARAMETRIC ANALYSIS

\begin{tabular}{|c|c|c|c|}
\hline Model & Column & Beam 1 & Beam 2 \\
\hline M1 & HEA200 & HEB300 & HEB140 \\
\hline M2 & HEA200 & HEB300 & HEB160 \\
\hline M3 & HEA200 & HEB300 & HEB180 \\
\hline M4 & HEA200 & HEB300 & HEB200 \\
\hline M5 & HEA200 & HEB400 & HEB180 \\
\hline M6 & HEA200 & HEB400 & HEB200 \\
\hline M7 & HEA200 & HEB400 & HEB240 \\
\hline M8 & HEA200 & HEB400 & HEB260 \\
\hline M9 & HEA240 & HEB300 & HEB140 \\
\hline M10 & HEA240 & HEB300 & HEB160 \\
\hline M11 & HEA240 & HEB300 & HEB180 \\
\hline M12 & HEA240 & HEB300 & HEB200 \\
\hline M13 & HEA240 & HEB400 & HEB180 \\
\hline M14 & HEA240 & HEB400 & HEB200 \\
\hline M15 & HEA240 & HEB400 & HEB240 \\
\hline M16 & HEA240 & HEB400 & HEB260 \\
\hline
\end{tabular}




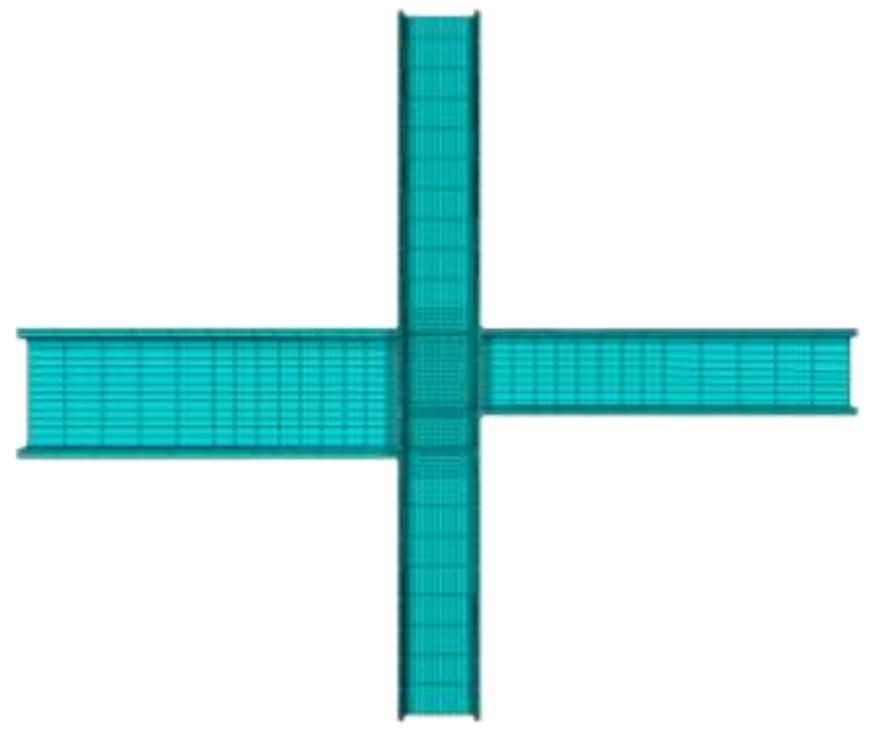

Figure 1. Finite element model

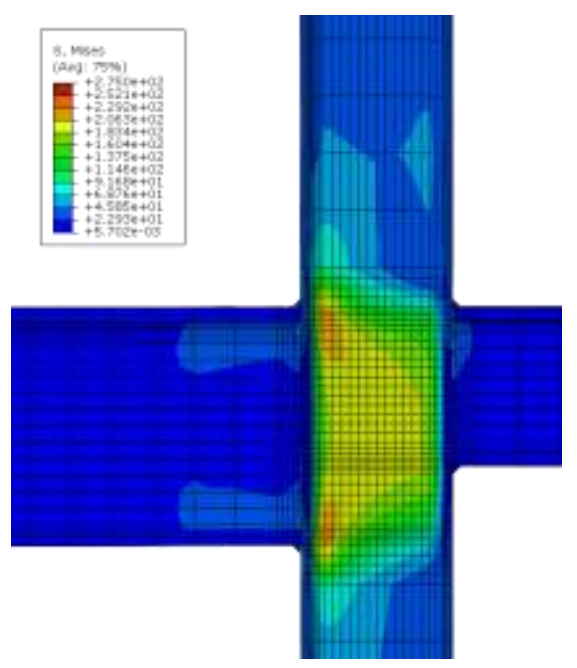

Figure 2. Von Misses stress when loading the deep beam

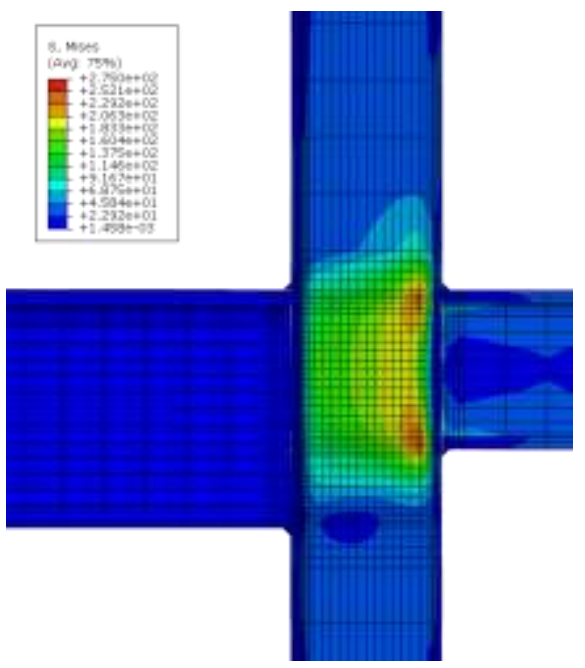

Figure 3. Von Misses stress when loading the shallow beam

Figure 1 shows a detail of the finite element model. Figures 2 and 3 show the Von Misses stresses when loading the deep beam and the shallow beam, respectively. It can be seen how, when the deep beam is loaded, the stresses extend over the whole panel, and when the shallow beam is loaded, the stresses are confined in a web area corresponding to the height of this beam.

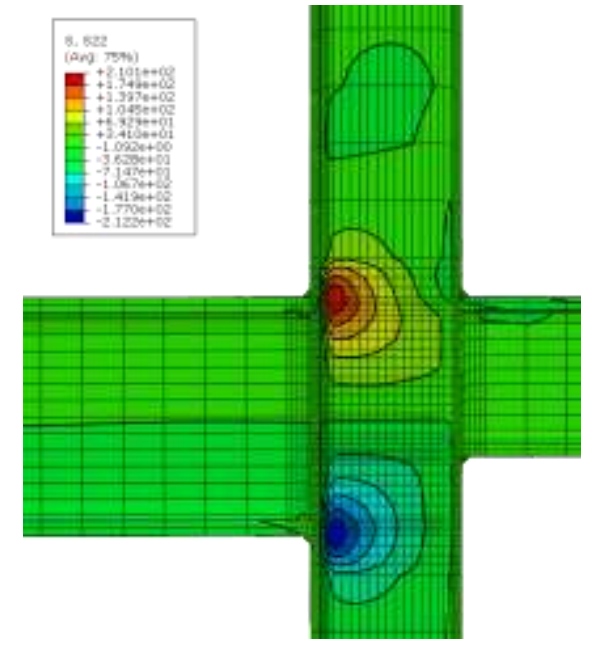

Figure 4. Elastic normal stresses when loading the deep beam

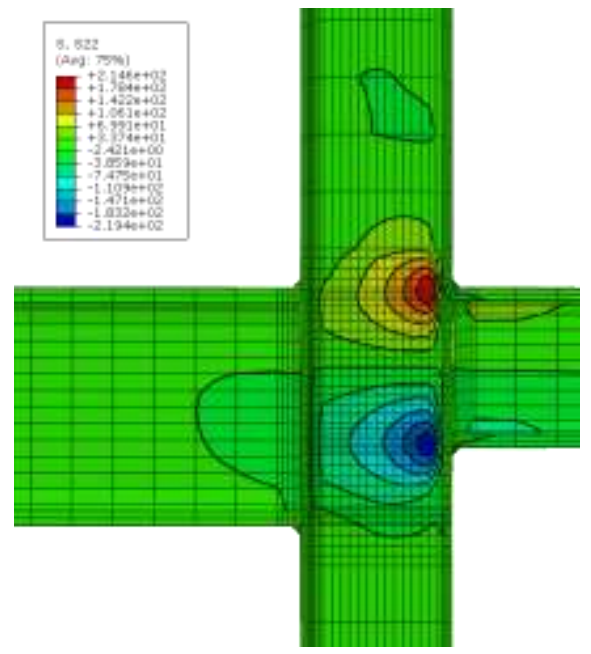

Figure 5. Elastic normal stresses when loading the shallow beam

Figures 4 and 5 show the tension and compression stress contours when loading the deep and the shallow sides, respectively. When the load is applied to the shallow side the compression coming from the lower flange of the shallow beam, is transmitted to the deep beam web. Consequently, it becomes necessary to include this effect in the mechanical model by means of the corresponding spring (component), as it will be explained below.

The moment-rotation curves have been obtained from the finite elements models for both, the deep and shallow beam sides. The study is centered in the linear range, with the aim of determining the stiffness of the joint in both cases. Thus, the results of stiffness for the posterior calibration of the mechanical model are obtained.

\section{Mechanical Model}

The proposed mechanical model is based in previous works developed by Bayo et al [7] [8]. The configuration of the model can be seen in Figure 6. 


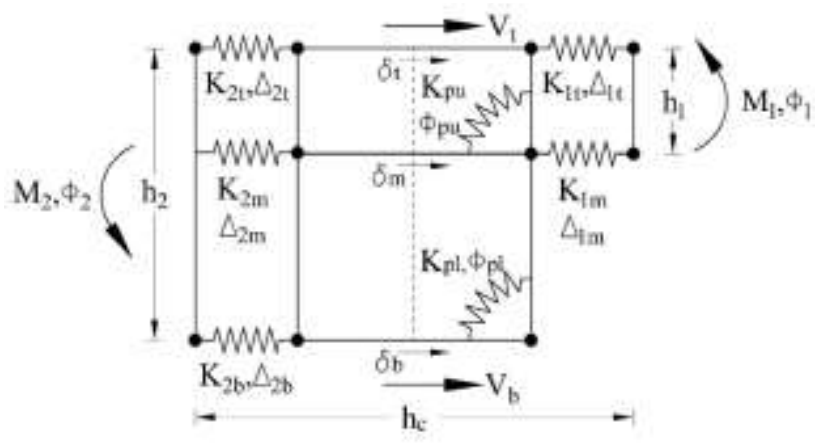

Figure 6. Mechanical Model

Most of the springs that configure the mechanical model and simulate the different components of the joint, have been described already in Loureiro et al [10]. Nevertheless, in the present research, in order to obtain the correct calibration of the mechanical model corresponding to the joint under study, the following components are developed:

$h$ : equivalent height of the joint

$h=h_{d b}+t_{f d b} / 2$

where, $h_{d b}$ is the height of the deep beam and $t_{f d b}$ is the flange thickness of the deep beam.

$h_{u}$ : equivalent height of the upper part of the panel

$h_{u}=h_{s b}+t_{f s b} / 2$

where, $h_{s b}$ is the height of the shallow beam and $t_{f s b}$ is the flange thickness of the shallow beam

$h_{l}$ : equivalent height of the low part of the panel

$h_{l}=h-h_{u}+t_{f d b} / 2$

where, $t_{f b b}$ is the flange thickness of the deep beam

$K_{p l}$ : stiffness of the equivalent spring of the lower column panel:

$K_{p l}=1.2 G A_{v c} h_{l}$

$K_{p u}$ : stiffness of the equivalent spring of the upper column panel:

$K_{p u}=1.25 G A_{v c} h_{u}$

where, $G$ is the shear modulus and $A_{v c}$ is the shear area of the column panel, as defined below (Krawinkler et al [1]):

$A_{v c}=\left(h_{c}-t_{c f}\right) t_{c w}$

where, $h_{c}$ is the height of the column, $t_{c f}$ is the thickness of the column flange and $t_{c w}$ is the thickness of the column web

$K_{2 m}$ stiffness of the equivalent spring in the web of the deep at the height of the lower flange of the shallow beam:

$K_{2 m}=0.7 h_{d b} t_{w d b} E / L_{e_{f}}$ where, $E$ is the Young's modulus, $t_{w d b}$ is the thickness of the deep beam web and $L_{e f}$ is the equivalent length of the axially loaded zone of the deep beam web, as shown below:

$L_{e_{f}}=2.5 h_{d b}$

$k_{d}$ is the stiffness of column web in compression and tension in the deep side.

$k_{d}=0.7 h_{e_{f f d}} t_{c w} E / d_{c}$

where, $h_{\text {effd }}$ and $d_{c}$ are the equivalent height and length of the axially loaded zone of the deep beam web, respectively, as defined below:

$h_{e f f d}=t_{f d b}+2 \sqrt{2} t_{s o l}+5\left(t_{c f}+r_{c}\right)$

$d_{c}=h_{c}-2\left(t_{c f}+r_{c}\right)$

where, $t_{s o l}$ is the throat thickness of the beam flange to column flange weld, and $r_{c}$ is the according ratio of the column.

$k_{s}$ is the stiffness of column web in compression and tension in the shallow side.

$k_{s}=0.7 h_{e_{f f s}} t_{c w} E / d_{c}$

where, $h_{\text {effs }}$ is the equivalent heigth of the axially loaded zone of the shallow beam web, as shown below:

$h_{e f f s}=t_{f s b}+2 \sqrt{2} t_{s o l}+5\left(t_{c f}+r_{c}\right)$

The stiffness of the rest of springs become:

$k_{1 T}=1.2 \cdot k_{s}$

$k_{1 M}=1.2 \cdot k_{s}$

$k_{2 T}=1.8 \cdot k_{d}$

$k_{2 B}=1.8 \cdot k_{d}$

\section{Results}

Once the mechanical model has been developed, the values of stiffness corresponding to the joints that have been analyzed in the FEM parametric study are \&pmpared to those obtained with the mechanical models. Figures 7 and 8 show the comparison for the deep and shallow beam, respectively. 


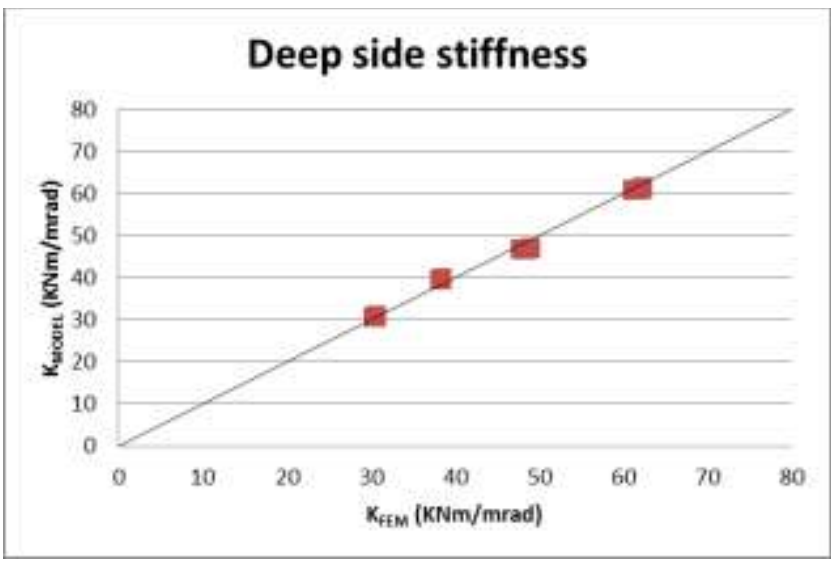

Figure 7. Comparison of the stiffness at the deep side between the FEM and the mechanical model when loading the deep beam

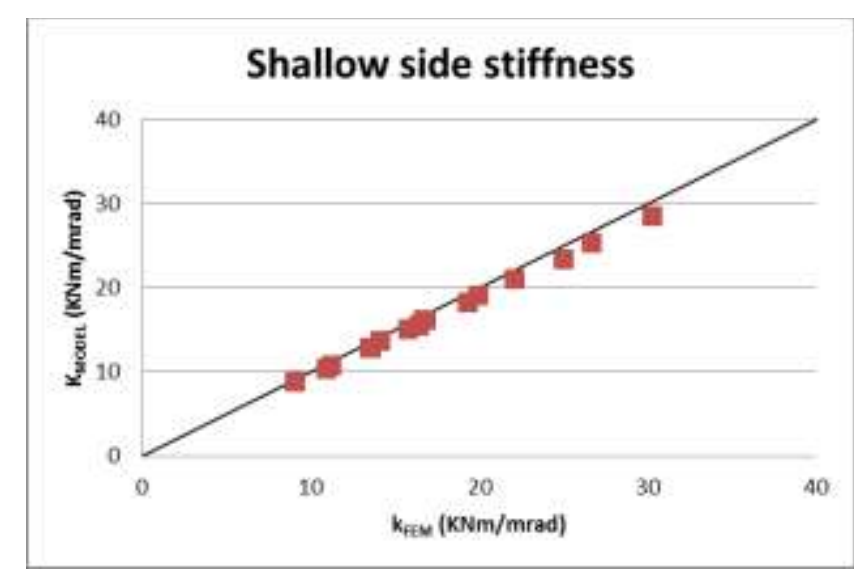

Figure 8. Comparison of the stiffness at the shallow side between the FEM and the mechanical model when loading the shallow beam

It can be seen that the results are quite accurate. The normalized mean value for the deep stiffness is 0.993 and the value of standard deviation of 0.027 . The mean value for the shallow stiffness is 1.046 and 0.012 for the standard deviation.

\section{v. Conclusions}

In the present research the behaviour of welded 2D beam to column steel joints with beams of different depth without web stiffeners have been carried out. A wide parametric analysis has been done based on previously calibrated finite elements models. The results of these analyses have been used to develop the formulation of the proposed mechanical model. The components of the mechanical model have been obtained.

It must be highlighted the presence of the component corresponding to the deep beam web in compression and tension $K_{2 m}$.

The results of the proposed mechanical model are very close to those obtained from the refined finite element models.

\section{Acknowledgment}

The financial support provided by the Spanish Ministerio de Economía y Competitividad under contracts BIA2013-
48069-C2-1-P and BIA2013-48069-C2-2-P is gratefully acknowledged.

\section{References}

[1] Krawinkler H, Bertero VV, Popov EP. Shear behaviour of steel frame joints. J Struct Div ASCE 1975; 101(11), pp.2317-2336

[2] Faella C, Piluso V, Rizzano G. Structural steel semi-rigid connections. Boca Raton: CRC Press; 2000

[3] Curtis H., Greiner G. A stress-based quadrilateral shear panel. Finite element analysis and design 1996; 21, pp.159-178

[4] Hashemi B.H., Jazany R.A. Study of connection detailing on SMRF seismic behaviour for unequal beam depths. Journal of Constructional Steel Research 2012; 68, pp.150-164

[5] CEN. Eurocode 3, EN 1993-1-8:2005: Design of steel structures. Part 1.8: Design of joints. Brussels, Belgium: European Committee for Standardization; 2005

[6] Bayo E., Cabrero J.M., Gil B. An effective component based method to model semi-rigid connections for the global analysis of steel and composite structures. Engineering Structures 2006: 28, pp.97-108

[7] Bayo E., Gracia J., Gil B., Goñi R. An efficient cruciform element to model semi-rigid composite connections for frame analysis. Journal of Constructional Steel Research 2012; 72, pp.97-104

[8] Bayo E, Loureiro A, Lopez M, Shear behaviour of trapezoidal column panels. I: Experiments and finite element modelling. Journal of Constructional Steel Research 2015; 108, pp.60-69

[9] Lopez M., Loureiro A., Bayo E. Shear behaviour of trapezoidal column panels. II: Parametric study and cruciform element. Journal of Constructional Steel Research 2015; 108, pp.70-81

[10] Loureiro A., Lopez M., Bayo E. Shear behaviour of stiffened double rectangular column panels: Characterization and cruciform element. Journal of Constructional Steel Research 2016: 117, pp.126-138 